\title{
Differentiation of Shigella species from Escherichia coli by glycerol dehydrogenase activity
}

\author{
O.M.M. Bouvet, P. Lenormand, V. Guibert and P.A.D. Grimont \\ Unité des Entérobactéries, Unité INSERM 389, Institut Pasteur, 75724 Paris Cedex 15
}

It has been determined that Escherichia coli and the four Shigella species (except $S$. boydii serotype 13) form a single genomospecies (Brenner, 1984). E. coli and the so-called Shigella species are biochemically and serologically closely related (Ewing, 1986). The " $O$ " antigens of many serotypes of Shigella are either identical to or closely related to those of $E$. coli (Ewing, 1986). The biochemical identification of Shigella sometimes presents difficulties in differentiating it from the biochemically atypical $E$. coli strains. The genus Shigella is composed of non-motile bacteria. With the exception of certain biotypes of S. flexneri 6, Shigella do not form gas from fermentable carbohydrates and, compared to Escherichia, Shigella are less active in their utilization of carbohydrates. Christensen's citrate, sodium acetate, sodium mucate and decarboxylation of lysine are of considerable value in the differentiation of members of the genus Shigella from Escherichia, particularly from anaerogenic nonmotile biotypes of $E$. coli (Ewing, 1986). Shigella do not grow fermentatively on Christensen's citrate; sodium mucate is utilized by some cultures of $S$. sonnei but not by other Shigella. Sodium acetate is utilized as a sole source of carbon by some biotypes of $S$. flexneri 4 a but not by other Shigella. Lysine is not decarboxylated by Shigella. The characteristic "invasiveness" of Shigella strains in the guinea pig keratoc : :junctivitis test (Sereny test) (Sereny, 1957) is als "shown by enteroinvasive $E$. coli.
The diversity of the glycerol pathway has been documented in enterobacterial species (Bouvet et al., 1994, 1995). Species which can grow fermentatively on glycerol possess typical enzymes of the anaerobic glycerol pathway (glycerol dehydrogenase type I (glyDH-I), dihydroxyacetone kinase, glycerol dehydratase and 1,3-propanediol dehydrogenase). $E$. coli cannot grow fermentatively un glycerol because of the abserre of enzymes of the anaerobic glycerol pathway. An $\mathrm{NAD}^{+}$-linked glycerol dehydrogenase, glyDH-II, induced by glycerol and hydroxyacetone (thus distinct from glyDH-I) responsible for salvaging the glycerol moiety of degradation products of phospholipids and triglycerides, has been described in $E$. coli (Jin et al., 1983; Lin, 1976; St. Martin et al., 1977; Tang et al., 1979, 1982). The structural gene of the $E$. coli glyDH-II has been mapped and cloned (Truniger and Boos, 1994). The identity of glyDH-II of $E$. coli with D-1-amino-2-propanol oxidoreductase has been reported and its participation in vitamin $B_{12}$ metabolism has been suggested (Kelley and Dekker, 1985). The levels of the glyDH-II activity are markedly induced by oxidized substrates (i.e. aminoacetone, hydroxyacetone, dihydroxyacetone). GlyDHs from a few bacterial species including Hafnia alvei and "Salmonella enterica" were found to be distinct from $E$. coli glyDH. GlyDH-III from $H$. alvei is induced by glycerol and not by hydroxyacetone whereas glyDH-IV of "S. enterica" is induced by hydrox- 
yacetone only (Bouvet et al., 1994). Recently, the distribution of glyDHs type I, II, III and IV and 1,3-propanediol dehydrogenase among the Enterobacteriaceae was studied (Bouvet et al., 1995). GlyDHs other than type I which are not associated with glycerol fermentation are widely distributed among the Enterobacteriaceae.

This study evaluated glyDHs as complementary tests for differentiating $E$. coli from Shigella species.

A total of 1,000 recent isolates belonging to E. coli (626 strains) and Shigella species (374 strains) from human clinical specimens (stool, urine, blood) or veterinary specimens (E. coli only) received at the French Salmonella and Shigella Reference Center (CNS) were included. $E$. coli strains belonging to 164 different $O$ serogroups had been received from the International Escherichia and Klebsiella Center. Biochemical identification and serotype determination were carried out by conventional methods (Ewing, 1986) and "Biotype-100" carbon source strips (BioMérieux, La Balme-les-Grottes, France) and software "Recognizer" (Institut Pasteur Taxolab, Paris, France). The study included 67 biochemically atypical $E$. coli strains. $E$. coli diarrhoeogenic pathotypes: enterotoxinogenic (ETEC), enteroinvasive (EIEC), enteropathogenic (EPEC) and enterohaemorrhagic (EHEC) types have been previously identified using DNA probes specific for pathogenicity genes (Bohnert et al., 1988). Two new serotypes 14 and 15 (Groo et al., 1989; Ansanuzzaman et al., 1995) of Shigella dysenteriae were included. All these strains were subcultured twice in Luria broth medium before performing the tests.

For the detection of glycerol dehydrogensse, bacteria were grown overnight at $30^{\circ} \mathrm{C}$ on tryptocasein soy agar plates (TCS, Diagnostics Pasteur, Marnes-la-Coquette, France) supplemented with $1 \%$ (vol/vol) glycerol or $70 \mathrm{mM}$ hydroxyacetone (HA) both sterilized by filtration. Cultures giown on TCS-glycerol were incubated in an anaerobic jar with catalyst, $\mathrm{H}_{2}+\mathrm{CO}_{2}$ generators (GasPak, BBL Becton Dickinson Microbiology Systems, Cockeysville, MD) and methylene blue indicator strip. Cultures grown on TCS-hydroxyacetone were incubated aerobically.

The bacterial growth from TCS-glycerol or TCS-hydroxyacetone agar plates was collected and suspended in reaction buffer to an absorbance (at $600 \mathrm{~nm}$ ) of about 0.6 . The reaction buffer contained $0.1 \mathrm{M} \mathrm{K}_{2} \mathrm{CO}_{3}, 30 \mathrm{mM}\left(\mathrm{NH}_{4}\right)_{2} \mathrm{SO}_{4}$ and was adjusted to $\mathrm{pH} 9.0$. It was stored in a well-stoppered bottle at $4^{\circ} \mathrm{C}$ up to one month. Bacterial suspensions from TCS-glycerol or TCS-hydroxyacetone agar plates were inmediately dispensed $(150 \mu \mathrm{l})$ into 96-well microtitre plates (Dynatech AG, Denkerdorf, Germany). Then, $30 \mu$ portions of a reagent (NAD, $210 \mathrm{mg}$; glycerol, $600 \mu \mathrm{l}$; nitro-blue tetrazolium, $42 \mathrm{mg}$; phenazine methosulphate, $2 \mathrm{mg}$; distilled water to $10 \mathrm{ml}$ ) (kept frozen at $-20^{\circ} \mathrm{C}$ in the dark) were added to the wells and the plates were gently shaken and incubated in the dark at room temperature. The plates were examined for the development of a purple colour within 15 to $30 \mathrm{~min}$. The colour in the uninoculated control medium remained unchanged (yellow). The control strains which we used were Serratia odorifera Grimont $10-73^{\mathrm{T}}$ (negative), and $E$. coli CNS $75-88$ (positive). To validate the test, five colonies of ten isolates were studied and no discrepancy was observed. Growth temperature $\left(30\right.$ or $37^{\circ} \mathrm{C}$ ) had no effect on the activity of this enzyme. Hydroxyacetone was from Aldrich (Strasbourg, France; cat. no. 13,818-5). All other biochemicals were obtained from Sigma Chemicals Co. (St. Louis, MO) and were reagent grade.

Table I indicates that $610 / 626(97 \%)$ of $E$. coli strains tested produced a glyDH type II induced by glycerol and hydroxyacetone, and no Shigella strain demonstrated such activity except $S$. flexneri serotype 6 biotype Manchester. The remaining $16 E$. coli strains lacking the glyDH-II were identified as follows: 8 biochemically typical $E$. coli, 7 biochemically atypical 
Table I. Distribution of glyDH induced by glycerol and/or hydroxyacetone, among $E$. coli and Shigella species.

GlyDH induced by:

\begin{tabular}{|c|c|c|}
\hline glycerol & hydr & oxyacetone \\
\hline$(610 / 626)^{(*)}$ & + & $(617 / 626)$ \\
\hline$(0 / 30)$ & - & $(0 / 30)$ \\
\hline$(0 / 22)$ & + & $(22 / 22)$ \\
\hline$(0 / 20)$ & $d$ & $(4 / 20)$ \\
\hline$(0 / 16)$ & $\dot{a}$ & $(13 / 16)$ \\
\hline$(0 / 15)$ & + & $(15 / 15)$ \\
\hline$(0 / 27)$ & - & $(0 / 27)$ \\
\hline$(0 / 4)$ & d & $(2 / 4)$ \\
\hline$(0 / 116)$ & - & $(0 / 116)$ \\
\hline$(4 / 4)$ & + & $(4 / 4)$ \\
\hline$(1 / 8)^{(* *)}$ & + & $(8 / 8)$ \\
\hline$(0 / 12)$ & + & $(12 / 12)$ \\
\hline$(0 / 10)$ & + & $(10 / 10)$ \\
\hline$(0 / 90)$ & - & $(0 / 90)$ \\
\hline
\end{tabular}

E. coli

S. boydii

serotypes $1,5,8,9,10,12,16,17,18$

serotypes $7,11,13,14,15$

serotypes 2,3

serotype 4

S. dysenteriae

serotype 1

serotypes $2,3,4,5,7,9,10,11,12,14,15$ serotypes 6,8

S. flexneri

serotypes $1,2,3,4,5, X, Y$

serotype 6 biotype Manchester

serotype 6 biotype Manchester "variant"

serotype 6 biotype Boyd 88

serotype 6 biotype Herfordshire

S. sonnei biotypes a, d, e, f, $g$

$\left(^{*}\right)+=97$ to $100 \%$ positive; $-=0$ to $1 \%$ pesitive; $d=2$ to $96 \%$ positive. The numbers in parentheses indicate the number of positive strains/number of strains tested. E. coli-negative strains were: CNS (French Salmonella Reference Center) 929876, CNS 85-209. CNS 87-249, CNS 87-299. CNS 930215, CNS 933112, CNS 937249, CNS 930888, CNS 930241, CNS 934567, CNS 933630, CNS 938458, CNS 931964, CNS 9311876, CNS 934103 and 4370-53.

(**) S. flexneri serotype 6 biotype Manchester "variant" positive strain was $165-88$.

E. coli (non-motile and/or not aerogenic, no decarboxylation of lysine) and one enteroinvasive $E$. coli.

A glyDH activity type IV, induced only by HA, was detected in a few serotypes of Shigella: $S$. dysenteriae serotype $1, S$. flexneri serotype 6 biotypes Boyd 88, Manchester "variant" and Herfordshire, and $S$. boydii serotypes $7,11,13,14$ and 15 . In contrast, all biotypes of $S$. sonnei, seven serotypes of $S$. flexneri, eleven serotypes of $S$. dysenteriae and nine serotypes of $S$. boydii gave negative results. Different results occurred in a few serotypes: $S$. dysenteriae serotypes 6 and 8 and $S$. boydii serotype 4 . Only the type strain and the strain used as reference in serological studies of $S$. boydii serotypes 2 and 3 gave a positive test.

$E$. coli and Shigella species are closely related genetically, biochemically and serologically, and intermediate strains may be difficult to identify. The glyDH test is a simple and rapid tool which can be an aid in differentiating Shigella from biochemically atypical $E$. coli strains in addition to common tests.

Key-words: Glycerol dehydrogenase, Shigella, Escherichia coli; Differentiation.

\section{Différenciation de Shigella de Escherichia coli par l'activité glycérol déshydrogénase}

Un test enzymatique simple, rapide et peu coûteux a été utilisé pour détecter la présence d'une glycérol-déshydrogénase de type II (induite par le glycérol et l'hydroxyacétone) ou de type IV (induite seulement par l'hydroxyacétone) chez 1.000 souches appartenant à Escherichia coli et Shigella. Une glycérol-déshydrogénase de type II a été trouvée chez $97 \%$ des souches de $E$. coli testées. Cette activité n'a été détectée chez aucune espèce de Shigella d l'exception de S. flexneri sérotype 6 biotype Manchester. Une glycérol-déshydrogénase de 
type IV a été trouvée chez $S$. dysenteriae sérotype I, $S$. flexneri sérotype 6 biotypes Boyd 88, Manchester "variant " et Herfordshire, et $S$. boydii sérotypes 7 , $11,13,14$ et 15 . Les autres sérotypes de Shigella ne présentent aucune de ces dє̇ix activités enzymatiques.

Mots-clés: Glycérol-déshydrogénase, Shigella, Escherichia coli; Différenciation.

\section{References}

Ansaruzzaman, M., Kibriya, A.K.M.G., Rahman, A., Neogi, P.K.B., Faruque, A.S.G., Rowe, B. \& Albert, M.J. (1995), Detection of provisional serovars of Shigella dysenteriae and designation as $S$. dysenteriae serotypes 14 and 15. J. Clin. Microbiol., 33, 1423-1425.

Bohnert, M.G., d'Hauteville, H.M. \& Sansonetti, P.J. (1988), Detection of enteric pathotypes of Escherichia coli by hybridization using six DNA probes. Ann. Inst. Pasteur/Microbiol., 139, 189-202.

Bouvet, O.M.M., Lenormand, P., Carlier, J.P. \& Grimont, P.A.D. (1994), Phenotypic diversity of anaerobic glycerol dissimilation shown by seven enterobacterial species. Res. Microbiol., 145, 129-139.

Bouvet, O.M.M., Lenormand, P., Ageron, E. \& Grimont, P.A.D. (1995), Taxonomic diversity of the anaerobic glycerol dissimilation in the Enterobacteriaceae. Res. Microbiol., 146, 279-290.

Brenner, D.J. (1984), Family I. Enterobacteriaceae, pp. 408-420, in "Bergeys's manual of systematic bacteriology", Krieg, N.R. and Holt, J.G. (ed.) vol. 1. Will ${ }^{\circ} \mathrm{ms}$ and Wilkins, Baltimore.
Ewing, W.H. (1986), Edwards and Ewing's identification of Enterobacteriaceae, 4th ed. Elsevier Science Publis., Amsterdam.

Groo, R.J., Thomas, L.V., Cheasty, T., Rowe, B. \& Lindberg, A.A. (1989), Four new provisional serovars of Shigella. J. Clin. Microbiol., 27, 829-831.

Jin, R.Z., Tang. J.C.-T. and Lin, E.C.C. (1983), Experimental evolution of a novel pathway for glycerol dissimilation in Escherichia coli. J. Mol. Evol., 19, 429436.

Kelley, J.J. \& Dekker, E.E. (1985), Identity of Escherichia coll D-1-amino-2-propanol:NAD+ oxidoreductase with $E$. coli glycerol dehydrogenase but not with Neisseria gonorrhoeae 1,2-propanediol:NAD ${ }^{+}$oxidoreductase. J. Bacteriol., 162, 170-175.

Lin, E.E. (1976), Glycerol dissimilation and its regulation in bacteria. Annu. Rev. Microbiol., 30, 535578.

Sereny, B. (1957), Experimental keratoconjunctivitis shigellosa. Acta. Microbiol. Acad. Sci. Hung., 4, 367376.

St. Martin, E.J., Freedberg, W.B. \& Lin, E.C.C. (1977), Kinase replacement by a dehydrogenase for Escherichia coli glycerol utilization. J. Bacteriol., 131, 10261028.

Tang, J.C.-T., Ruch, F.E., Jr \& Lin, E.C.C. (1979), Purification and properties of nicotinamide adenine dinucleotide-linked dehydrogenase that serves an Escherichia coli mutant for glycerol catabolism. J. Bacteriol., 140, 182-187.

Tang, J.C.-T., St. Martin, E.J. \& Lin, E.C.C. (1982), Derepression of an NAD-linked dehydrogenase that serves an Escherichia coli mutant for growth on glycerol. J. Bacteriol., 152, 1001-1007.

Truniger, V. \& Boos, W. (1994), Mapping and cloning of gldA, the structural gene of the Escherichia coli glycerol dehydrogenase. J. Bacteriol., 176, 17961800. 